\title{
Proteinaceous exotoxins of shrimp-pathogenic isolates of Vibrio penaeicida and Vibrio nigripulchritudo
}

\section{Exotoxinas proteicas de cepas de Vibrio penaeicida y Vibrio nigripulchritudo, patogénicas para camarón}

\author{
Gabriel Aguirre-Guzmán ${ }^{1}$ \\ Yannick Labreuche ${ }^{2}$ \\ Dominique Ansquer ${ }^{2}$ \\ Benoît Espiau \\ Peva Levy ${ }^{2}$ \\ Felipe Ascencio ${ }^{1}$ \\ Denis Saulnier ${ }^{2 *}$ \\ ${ }^{1}$ Centro de Investigaciones Biológicas del Noroeste (CIBNOR) \\ Unidad de Patología Marina \\ La Paz, Baja California Sur, México \\ ${ }^{2}$ Laboratoire d'Aquaculture Tropicale \\ Centre Océanologique du Pacifique, IFREMER \\ *E-mail: Denis.Saulnier@ifremer.fr
}

Recibido en junio de 2002; aceptado en octubre de 2002

\begin{abstract}
The pathogenicity of two V. penaeicida strains, AM101 and KH-1, with different geographic origin, and V. nigripulchritudo strain AM102, were investigated in juvenile blue shrimp species Litopenaeus stylirostris. Alive bacteria and protein fractions (PFs) obtained from cell-free supernatants (CFS) were used in experimental challenges. Strains AM102, AM101, and KH-1 produced respectively 60,54 and $12 \%$ mortality at $96 \mathrm{~h}$ after infection using $10^{4} \mathrm{cfu} \mathrm{mL}^{-1}$ of bacterial suspension. Exocellular toxin-like factors were evidenced in CFS from the New Caledonian strains (AM102 and AM101) but not in the Japanese strain (KH-1). At 48 h post injection of each CFS, mortality rates were respectively 96,98 and $5 \%$ when these strains were cultivated at $20^{\circ} \mathrm{C}$, whereas only 0,16 and $5 \%$ mortality rates were observed when these strains were cultivated at $30^{\circ} \mathrm{C}$. Clear differences in pathogenicity between both V. penaeicida strains of distinct geographic origin (AM101 and KH-1) were thus emphasized. Protein fractions were obtained from CFS of all the strains tested in this study and cultivated at $20^{\circ} \mathrm{C}$, by ammonium sulfate precipitation. Whatever the used strain, significantly higher mortalities were produced with PFs obtained with $0-40 \%$ of ammonium sulfate saturation, in respect to those produced with PFs60 and PFs80. Shrimp injected with PFs40 from strains AM102, AM101 and $\mathrm{KH}-1$, and at a $20-\mu \mathrm{g}$ org $^{-1}$ dose produced respectively 100,90 and $60 \%$ mortality $46 \mathrm{~h}$ after the challenge. The strain AM101 showed a median lethal dose of approximately $5 \mu \mathrm{g}$ protein $\operatorname{org}^{-1}\left(1-1.25 \mu \mathrm{g}\right.$ protein $\mathrm{g}^{-1}$ body weight $) 59 \mathrm{~h}$ after injection. The PFs40 from New Caledonian strains were found sensitive to heating and proteinase $\mathrm{K}$ treatments, reinforcing thus the hypothesis of their proteinaceous nature. Surprisingly, PFs40 from each bacterial strain displayed similar protein bands by SDS-PAGE suggesting that the tested strains share a common exotoxic compound regardless their distinct geographic origin or species.
\end{abstract}

Key words: Vibrio penaeicida, Vibrio nigripulchritudo, Litopenaeus stylirostris, shrimp, exotoxin, pathogenicity.

\section{Resumen}

La patogenicidad de dos cepas de V. penaeicida, AM101 y KH-1, con diferente origen geográfico, y de la cepa AM102 de $V$. nigripulchritudo fue investigada en camarones azules juveniles de la especie Litopenaeus stylirostris. Las bacterias vivas y las fracciones proteicas (FPs) obtenidas del sobrenadante libre de células (SLC) fueron usadas en un ensayo experimental. Las cepas AM102, AM101 y KH-1 produjeron respectivamente una mortalidad de 60, 54 y 12\%, 96 h después de la infección al usar una suspensión bacteriana de $10^{4}$ ufc $\mathrm{mL}^{-1}$. Factores tipo toxina exocelular fueron evidenciados en los SLC de las cepas de Nueva Caledonia (AM102 y AM101) pero no en la cepa japonesa (KH-1). A 48 h post-inyección de cada SLC, el porcentaje de mortalidad fue respectivamente de 96,98 y $5 \%$ cuando estas cepas fueron cultivadas a $20^{\circ} \mathrm{C}$, mientras que sólo 0,16 , y $5 \%$ de mortalidad fue observado cuando las cepas fueron cultivadas a $30^{\circ} \mathrm{C}$. Se observó una clara diferencia en la patogenicidad entre las dos cepas de V. penaeicida provenientes de diferentes orígenes geográficos (AM101 y KH-1). Las FPs fueron obtenidas a partir del SLC de todas las cepas cultivadas a $20^{\circ} \mathrm{C}$, por medio de precipitación con sulfato de amonio. Se obtuvo una mortalidad significativa con las FPs precipitadas con $40 \%$ de sulfato de amonio, en comparación con las precipitadas con 60 y $80 \%$. Los camarones inyectados con FPs40 de AM102, AM101 y KH-1 a una dosis de $20 \mu \mathrm{g}$ de proteína org $^{-1}$ tuvieron una mortalidad de 
100, 90 y 60\%, respectivamente, 46 h después del ensayo. La cepa AM101 mostró una dosis letal media de aproximadamente $5 \mu \mathrm{g}$ proteína org $^{-1}\left(1-1.25 \mu \mathrm{g}\right.$ de proteína $\mathrm{g}^{-1}$ de peso del cuerpo), $59 \mathrm{~h}$ después de ser inyectada. Las FPs40 de las cepas de Nueva Caledonia fueron sensibles al tratamiento con calor y proteinasa K, reforzando la hipótesis de su naturaleza proteica. Sorpresivamente, las FPs40 de cada cepa bacteriana mostraron bandas proteicas similares cuando se analizaron por SDS-PAGE, sugiriendo que las cepas ensayadas comparten un elemento exotóxico en común, independientemente de su diferente origen geográfico.

Palabras claves: Vibrio penaeicida, Vibrio nigripulchritudo, Litopenaeus stylirostris, camarón, exotoxina, patogenicidad.

\section{Introduction}

The commercial shrimp aquaculture systems are plagued by different diseases that affect shrimp survival and growth. Vibrio species are opportunist bacteria or true pathogens that take advantages of ecological changes introduced by aquaculture, causing a serious loss in the shrimp production (Lightner 1988; Brock and LeaMaster 1992; Costa et al., 1998). The effects of Vibrio and severity of vibriosis are a function of the following factors: Vibrio species and strains, their concentration in shrimp microflora or rearing water, water quality, shrimp species and age, and management practices (Prayitno and Latchford 1995; Lightner 1996; Saulnier et al., 2000a). Vibrio species that have caused high mortality of shrimp include $V$. penaeicida, $V$. campbellii, $V$. harveyi, $V$. nigripulchritudo, V. parahaemolyticus, and $V$. alginolyticus (de la Peña et al., 1993; 1995; Jiravanichpaisal et al., 1994; Karunasagar et al., 1994; Hameed 1995; Alapide-Tendencia and Dureza, 1997; Lee et al., 1997; Costa et al., 1998; Robertson et al., 1998).

Vibrio nigripulchritudo and $V$. penaeicida were reported as the principal bacteria involved in the outbreak of disease found in L. stylirostris shrimp farm production in New Caledonia (Costa et al., 1998). Another V. penaeicida strain was considered a serious problem in the P. japonicus shrimp culture in Japan (Ishimaru et al., 1995). The virulence of some $V$. penaeicida and $V$. nigripulchritudo strains, including those used in this study, was detected by experimental infections of juvenile L. stylirostris (Le Groumellec et al., 1996; Saulnier et al., 2000b) or P. japonicus (de la Peña et al., 1993, 1995). Experimentally infected shrimp suffered severe bacterial invasion as revealed by some pathogenesis studies (de la Peña et al., 1995; Saulnier et al., 2000b).

Besides the demonstration of active infections, extracellular products (ECP) obtained by in vitro cultivation of particular Vibrio strains have been implicated as a virulence factor in a wide range of marine organisms (Fukasawa et al., 1988; Liu et al., 1996; Sainz et al., 1998; Montero and Austin 1999; Hörmansdorfer et al., 2000). In two different shrimppathogenic isolates of Vibrio harveyi Liu et al. (1996), Lee et al. (1999) and Montero and Austin (1999) have suggested that a cysteine protease and lipopolysaccharides respectively constituted the major toxins produced by the bacteria. Goarant $e t$ al. (2000) showed toxic activities of ECP from the same $V$. penaeicida and $V$. nigripulchritudo strains used in this study, when injected into juvenile L. stylirostris and used in vitro assays on haemocyte primary cell cultures. Interestingly, the in

\section{Introducción}

Los sistemas comerciales de acuicultura de camarón están plagados de diferentes enfermedades que afectan la sobrevivencia y crecimiento de los organismos. Los Vibrio son bacterias oportunistas o patógenos verdaderos que aprovechan los cambios ecológicos que se generan por la acuicultura, causando perdidas importantes en la producción del camarón (Lightner 1988; Brock y LeaMaster 1992; Costa et al., 1998). Los efectos de Vibrio y la severidad de la vibriosis están en función de los siguientes factores: la especie y cepa del Vibrio, su concentración en la microflora del camarón o del agua, la calidad del agua, la especie de camarón y su edad, y las prácticas de manejo (Prayitno y Latchford 1995; Lightner 1996; Saulnier et al., 2000a). Las especies de Vibrio que causan altas mortalidades en el camarón incluyen a $V$. penaeicida, $V$. campbellii, $V$. harveyi, $V$. nigripulchritudo, $\quad V$. parahaemolyticus y $V$. alginolyticus (de la Peña et al., 1993, 1995; Jiravanichpaisal et al., 1994; Karunasagar et al., 1994; Hameed 1995; Alapide-Tendencia y Dureza 1997; Lee et al., 1997; Costa et al., 1998; Robertson et al., 1998).

Vibrio nigripulchritudo y $V$. penaeicida fueron reportados como los principales responsables del daño en la producción del camarón L. stylirostris en las granjas de Nueva Caledonia (Costa et al., 1998). Otra cepa de V. penaeicida fue considerada como un serio problema para el cultivo de camarón $P$. japonicus en Japón (Ishimaru et al., 1995). La virulencia de algunas cepas de $V$. penaeicida y $V$. nigripulchritudo, incluyendo las usadas en este experimento, fue observada por infecciones experimentales en juveniles de L. stylirostris (Le Groumellec et al., 1996; Saulnier et al., 2000b) o P. japonicus (de la Peña et al., 1993, 1995). Los camarones infectados experimentalmente sufrieron una severa invasión bacteriana como lo revelan algunos estudios de patogenicidad (de la Peña et al., 1995; Saulnier et al., 2000b).

Además de la demostración de la infección activa, productos extracelulares (PEC) obtenidos de cultivos in vitro a partir de cepas particulares de Vibrio han sido implicados como factor de virulencia en un gran rango de organismos marinos (Fukasawa et al., 1988; Liu et al., 1996; Sainz et al., 1998; Montero y Austin 1999; Hörmansdorfer et al., 2000). En dos diferentes cepas de Vibrio harveyi aisladas de camarones enfermos (Liu et al., 1996; Lee et al., 1999; Montero y Austin 1999) se ha sugerido que la cistein-proteasa y los lipopolisacaridos, respectivamente, constituyen las principales exotoxinas producidas por esta bacteria. Goarant et al. (2000) mostraron la actividad tóxica de los PEC de las mismas cepas de 
vivo toxicity of ECP from $V$. penaeicida was found only when bacteria were cultivated at $20^{\circ} \mathrm{C}$ and not at higher temperature $\left(25\right.$ or $\left.30^{\circ} \mathrm{C}\right)$.

In this study, three Vibrio strains known to be shrimp pathogens were used to experimentally infect juvenile L. stylirostris under environmentally controlled culture conditions. Because the severity of vibriosis is partly related to the Vibrio species, bacterial strains and shrimp species, the pathogenicity of two Vibrio strains (AM101 and AM102) from the same geographic origin (New Caledonian) but different species and two strains (KH-1 and AM101) from the same Vibrio species but from different geographic origin and originally isolated from two different shrimp species, was compared. Emphasis was put upon the pathogenicity of some protein fractions (PFs) obtained by sequential ammonium sulfate precipitation of cell free supernatants (CFS) from in vitro culture of these strains, in order to further facilitate the purification and identification of the virulence factors involved.

\section{Materials and methods}

Vibrio strains and culture condition

Vibrio penaeicida strain AM101 and $V$. nigripulchritudo strain AM102 were isolated from haemolymph of syndrome 93-diseased L. stylirostris shrimp in a New Caledonian shrimp farm. The species to which these two Vibrio belonged was identified by DNA-DNA hybridization assays and arbitrarily primed PCR fingerprinting (Costa et al., 1998; Goarant et al., 1999). Vibrio penaeicida KH-1 reference strain (Ishimaru et al., 1995) was isolated from diseased P. japonicus shrimp in Japan. Although strains AM101 and KH-1 belonged both to $V$. penaeicida, genotypic differences were revealed by ribotyping and arbitrarily primed PCR fingerprinting (Costa et al., 1998; Goarant et al., 1999). Bacteria stored at $-80^{\circ} \mathrm{C}$ were revived in marine agar (Diagnostics Pasteur, Marnes la Coquette, France) petri dishes and incubated at $27^{\circ} \mathrm{C}$ for $24 \mathrm{~h}$. Before their use, the culture purity and the main physiological and biochemical characteristics of the strains were checked.

Preparation of cell free supernatants and protein fractions

Each Vibrio strain was cultured on $0.5 \mathrm{~L}$ nutrient medium containing brain heart infusion (BHI, Diagnostic Pasteur) (Goarant et al., 2000) and artificial seawater $(2.3 \% \mathrm{wt} / \mathrm{vol}$ $\mathrm{NaCl}, 20 \mathrm{mM} \mathrm{KCl}, 5 \mathrm{mM} \mathrm{MgSO}_{4}, 2 \mathrm{mM} \mathrm{CaCl}_{2}$ ) under constant stirring at 20 and $30^{\circ} \mathrm{C}$ for $48 \mathrm{~h}$ and $24 \mathrm{~h}$, respectively. Cell free supernatants (CFS) were prepared by centrifugation at $4000 \times g$ for $10 \mathrm{~min}$ at $4^{\circ} \mathrm{C}$ from each bacterial suspension, followed by filtration through a $0.2-\mu \mathrm{m}$ pore size filter. A control was prepared using a sterilized and filtered BHI. The sterility of all CFS and nutrient medium were verified by spreading $100 \mu \mathrm{l}$ of each preparation onto reconstituted marine agar plates and incubating plates at $27^{\circ} \mathrm{C}$ at least of $16 \mathrm{~h}$. Only CFS obtained from bacterial strains cultivated at $20^{\circ} \mathrm{C}$
$V$. penaeicida y $V$. nigripulchritudo usadas en este estudio cuando fueron inyectados a juveniles de L. stylirostris y usados en ensayos in vitro sobre cultivos primarios de hemocitos. De manera interesante, la toxicidad in vivo de los PEC de $V$. penaeicida fue encontrada sólo en las bacterias cultivadas a $20^{\circ} \mathrm{C}$ y no a mayor temperatura $\left(25\right.$ o $\left.30^{\circ} \mathrm{C}\right)$.

En este estudio, tres cepas de Vibrio conocidas como patógenas para camarón fueron usadas para infectar experimentalmente a juveniles de L. stylirostris bajo condiciones de cultivo en ambiemte controlado. Debido a que la severidad de la vibriosis está parcialmente relacionada con la especie y cepa del Vibrio, así como con la especie del camarón, se comparó la patogenicidad de dos cepas de Vibrio (AM101 y AM102) con el mismo origen geográfico (Nueva Caledonia) y de diferente especie, y dos cepas (KH-1 y AM101) de la misma especie de Vibrio pero con diferente origen geográfico, las cuales fueron originalmente aisladas de diferentes especies de camarón. Se hizo énfasis en la patogenicidad de algunas fracciones proteicas (FPs) obtenidas a partir de precipitaciones consecutivas con sulfato de amonio del sobrenadante libre de células (SLC) de cultivos in vitro de estas cepas, a fin de facilitar la purificación e identificación de los factores de virulencia involucrados.

\section{Materiales y métodos}

Cepas de Vibrio y condiciones de cultivo

Las cepa AM101 de $V$. penaeicida y la AM102 de $V$. nigripulchritudo fueron aisladas de la hemolinfa de camarones enfermos durante el síndrome 93 de enfermedades de $L$. stylirostris en las granjas de cultivo de Nueva Caledonia. La identificación de estas dos especies de Vibrio fue realizada por pruebas de hibridación DNA-DNA y con el uso de PCR (Costa et al., 1998; Goarant et al., 1999). La cepa de referencia KH-1 de $V$. penaeicida (Ishimaru et al., 1995) fue aislada de camarones $P$. japonicus enfermos, en Japón. Además, aunque las cepas AM101 y KH-1 fueron ambas identificadas como $V$. penaeicida, se encontraron diferencias en su genotipo por medio de ribotyping y PCR (Costa et al., 1998; Goarant et al., 1999). Las bacterias fueron almacenadas $\mathrm{a}-80^{\circ} \mathrm{C}$ y reactivadas sembrando por estría en cajas petri con agar marino (Diagnostics Pasteur, Marnes la Coquette, Francia) e incubadas a $27^{\circ} \mathrm{C}$ por $24 \mathrm{~h}$. Antes de su uso, las características fisiológicas $\mathrm{y}$ bioquímicas generales de las cepas fueron revisadas en cultivos puros.

Preparación del sobrenadante libre de células y fracciones proteicas

Cada cepa de Vibrio fue cultivada en 0.5 L de medio nutritivo con caldo cerebro-corazón (BHI, Diagnostic Pasteur) (Goarant et al., 2000) y agua marina artificial (2.3\% peso/vol $\mathrm{NaCl}, 20 \mathrm{mM} \mathrm{KCl}, 5 \mathrm{mM} \mathrm{MgSO}, 2 \mathrm{mM} \mathrm{CaCl}_{2}$ ) bajo condiciones constantes de agitación a 20 y $30^{\circ} \mathrm{C}$, por $48 \mathrm{~h}$ y 
incubation temperature were further used to prepare consecutive protein fractions (PFs) by sequential ammonium sulfate precipitation. Salt was gently added under slow stirring to $0.5 \mathrm{~L}$ of each CFS maintained at $4^{\circ} \mathrm{C}$ until 40,60 , and $80 \%$ saturation (w/v) was reached (Harlow and Lane 1988; Scopes 1998). Between each saturation step, the resulting mixture was stored overnight at $4^{\circ} \mathrm{C}$. Protein precipitate fractions (PFs40, PFs60 and PFs80) were serially collected by centrifugation at $4400 \times g$ for $30 \mathrm{~min}$ at $4^{\circ} \mathrm{C}$ (Hernández-Sontoyo et al., 1998). Each PF was then suspended in $10 \mathrm{~mL}$ of sterilized and distillated water and dialyzed against distilled water at $4^{\circ} \mathrm{C}$ for $72 \mathrm{~h}$ using semi-permeable dialysis bags (SIGMA, USA) at a $12,000 \mathrm{kDa}$ cut off.

\section{Protein determination}

Soluble protein concentrations in each dialyzed PFs40, PFs60 and PFs80 were evaluated using a microprotein determination test (SIGMA), based on a modified procedure of the standard method by Biuret and Lowry (Ohnishi and Barr, 1978) at a 750-nm lengthweight. Bovine serum albumin was used to determine a standard curve.

\section{Experimental animals}

In this study, different batches of juvenile shrimp (L. stylirostris) were reared in captivity at Aquapac, Co. shrimp farm in Tahiti and transported to the Centre Océanologique du Pacifique (COP) experimental facilities. Shrimps belonging to the infectious hypodermal and haematopoietic necrosis virus-specific pathogen-resistant strain (SPR43) were acclimated to laboratory conditions in tanks supplied with filtered and aerated seawater (3- $\mu \mathrm{m}$ pore-size filter), aeration and no substrate bed for at least two days. The environmental variables of the filtered seawater measured during the study were: $\mathrm{pH} 7.8-8.2$, temperature $24-26^{\circ} \mathrm{C}$ and salinity $35 \%$. Juvenile shrimp were fed ad libitum with extruded feed for shrimp containing $40 \%$ crude protein and produced in a local factory (Huilerie de Tahiti) according to the COP's formulation. Shrimp mortality was monitored and the results were expressed in mortality rate (\%) according to the formula:

$$
\text { Mortality }(\%)=\frac{\text { Final number of dead organisms }}{\text { Initial number of organisms }} \times 100 \text {. }
$$

\section{Shrimp infection with living Vibrio strains}

All Vibrio strains were cultured in Zobell's liquid nutrient medium at $30^{\circ} \mathrm{C}$ under vigorous stirring by $16 \mathrm{~h}$. Afterwards, bacterial suspensions were ten-fold serially diluted with artificial seawater (Saulnier et al., 2000a). Colony Forming units (cfu) of each bacterial suspension sample $(100 \mu \mathrm{L})$ were spread and cultured at $27^{\circ} \mathrm{C}$ for $16 \mathrm{~h}$ in Zobell's nutrient agar plates to check a posteriori the number of bacteria used in the experimental challenges. All experimental challenges were
24 h respectivamente. El SLC fue preparado por centrifugación a $4,000 \times g$ por $10 \mathrm{~min}$ a $4^{\circ} \mathrm{C}$, a partir de cada suspensión bacteriana, seguido por una filtración a través de un filtro con un tamaño de poro de $0.2 \mu \mathrm{m}$. Se preparó un control usando BHI esterilizado y filtrado. La esterilidad de cada SLC y del medio nutritivo fue verificada al sembrar por extensión en superficie $100 \mu \mathrm{l}$ de cada preparación sobre placas de agar marino reconstituido, e incubando a $27^{\circ} \mathrm{C}$ por un mínimo de 16 h. Solo los SLC de las bacterias cultivadas a $20^{\circ} \mathrm{C}$ fueron posteriormente usados para la obtención de fracciones proteicas consecutivas (FPs) por medio de precipitación con sulfato de amonio. Se adicionó sal de amonio, con agitación lenta, a $0.5 \mathrm{~L}$ de cada SLC mantenido a $4^{\circ} \mathrm{C}$ hasta una saturación de 40, 60 y $80 \%$ (p/v) (Harlow y Lane 1988; Scopes 1998). Entre cada etapa de saturación, la mezcla resultante fue almacenada durante la noche a $4^{\circ} \mathrm{C}$. Las fracciones de proteína precipitada (FPs40, FPs60 y FPs80) fueron colectadas en serie por centrifugación a $4,400 \times g$ por $30 \mathrm{~min}$ a $4^{\circ} \mathrm{C}$ (Hernández-Sontoyo et al., 1998). Cada FPs fueron suspendidas en $10 \mathrm{~mL}$ de agua destilada estéril, y dializadas en agua destilada a $4^{\circ} \mathrm{C}$ por $72 \mathrm{~h}$, usando para este fin una bolsa de diálisis semipermeable (SIGMA, USA) con un tamaño de poro de 12,000 kDa.

Determinación de la proteína

La concentración de la proteína soluble de las fracciones FPs40, FPs60 y FPs80 dializadas fue medida usando un kit de microdeterminación (SIGMA) basado en un procedimiento modificado del método estándar de Biuret y Lowry (Ohnishi y Barr, 1978), a $750 \mathrm{~nm}$ de longitud de onda. Se usó albúmina bovina para realizar una curva estándar.

Animales usados en el experimento

Para este estudio se usaron diferentes lotes de camarones juveniles (L. stylirostris) obtenidos de la granja Aquapac, Co., los cuales fueron transportados hacia el área experimental del Centre Océanologique du Pacifique (COP). Los camarones pertenecían a la línea resistente al virus de la infección hipodermal y necrosis hepatopancreatitis (SPR43), y fueron aclimatados por dos días a las condiciones de laboratorio en tanques con agua de mar filtrada (con poro de $3 \mu \mathrm{m}$ ), aireada y sin substrato. Las variables ambientales del agua filtrada durante este estudio fueron $\mathrm{pH} 7.8-8.2$, temperatura $24-26^{\circ} \mathrm{C}$ y salinidad 35\%o. Los camarones juveniles fueron alimentados ad libitum con alimento extruido para camarón con $40 \%$ de proteína cruda y producido en una empresa local (Huilerie de Tahiti), de acuerdo a una formulación realizada en el COP. La mortalidad de los camarones fue monitoreada y el resultado fue expresado en porcentaje (\%) de mortalidad de acuerdo a la formula:

$$
\text { Mortalidad }(\%)=\frac{\text { Número final de organismos muertos }}{\text { Número inicial de organismos }} \times 100 \text {. }
$$


conducted in a controlled area since $V$. penaeicida and V. nigripulchritudo have not been reported in Tahiti. Shrimp ( 3.5 to $5.0 \mathrm{~g}$ weight) were infected by immersion for $2 \mathrm{~h}$ in 10 $\mathrm{L}$ of filtered and aerated seawater containing $1-3.5 \times 10^{4} \mathrm{cfu}$ $\mathrm{mL}^{-1}$ of bacterial strain. After the challenge, batches of 25 shrimps were carefully transferred to cylindrical-conical plastic tanks with $100 \mathrm{~L}$ of filtrated seawater and aeration. Control shrimp were treated as above except for the addition of the pathogenic strain. Two culture tanks were used for each treatment as replicates.

\section{Shrimp injection with CFS and PFs}

Shrimp (2.5 to $4.0 \mathrm{~g}$ weight) were injected with $60 \mu \mathrm{L}$ of each CFS obtained at 20 or $30^{\circ} \mathrm{C}$ incubation temperature. Similarly, shrimps were intramuscularly injected with $20 \mu \mathrm{g}$ protein $\operatorname{org}^{-1}(20 \mu \mathrm{L})$ of dialyzed PFs40, PFs60, and PFs80 obtained from each pathogenic CFS or the control (BHI). Each organism was injected intra-muscularly between the third and fourth abdominal segments. Two control groups were used (not injected and injected with $60 \mu \mathrm{L}$ of $\mathrm{BHI}$ ). Each shrimp treatment, in duplicate, was transferred to cylindrical-conical plastic tanks with $100 \mathrm{~L}$ of filtrated seawater and aerated, at a density of 20 to 25 shrimps per tank.

In order to calculate a median lethal dose $\left(\mathrm{LD}_{50}\right)$ of PFs 40 for strain AM101, shrimp (4 to $5 \mathrm{~g}$ weight) were injected at different doses $\left(1,5,10\right.$ and $20 \mu \mathrm{g}$ protein $\left.\operatorname{org}^{-1}\right)$ using the same protocol as above.

\section{Thermal and chemical treatments on PFs40}

The PFs40 from strain AM101 and strain AM102 were subjected to the following thermal and chemical treatments before being injected intra-muscularly $\left(20 \mu \mathrm{g}\right.$ protein $\mathrm{org}^{-1}$, quantified before treatment) as described by Montero and Austin (1999): (1) heat at 60 and $100^{\circ} \mathrm{C}$ for $10 \mathrm{~min}$, (2) digestion with proteinase $\mathrm{K}$ at a $100-\mu \mathrm{g} \mathrm{mL}^{-1}$ final concentration, for $1 \mathrm{~h}$ at $37^{\circ} \mathrm{C}$, (3) exposure to a soybean trypsin inhibitor at a $200-\mu \mathrm{g} \mathrm{mL}^{-1}$ final concentration of ; or (4) exposure to EDTA at a $100-\mu \mathrm{M}$ final concentration. Control shrimp groups were injected with one of the three chemical products at the same concentrations that were previously used. All injected shrimps were transferred to cylindrical-conical plastic tanks with $100 \mathrm{~L}$ of filtered and aerated sea water, at a density of 20 shrimp per tank.

\section{SDS-polyacrylamide gel electrophoresis of PFs40}

The protein band profile from the PFs40 from strains AM101, KH-1 and AM102 was obtained by SDS-PAGE. The PFs40 were denatured in sample buffer for $10 \mathrm{~min}$ at $96^{\circ} \mathrm{C}$ (Laemmli, 1970), and then loaded on a SDS-polyacrylamide (Sambrook et al., 1989) at $110 \mathrm{~V}$ for $1.4 \mathrm{~h}$. Protein bands were stained with $0.2 \% \mathrm{AgNO}_{3}$ solution $\left(200 \mu \mathrm{g}\right.$ of $\mathrm{AgNO}_{3}, 75 \mathrm{~mL}$
Infección de los camarones con las cepas vivas de Vibrio

Todas las cepas de Vibrio fueron cultivadas en medio nutritivo líquido de Zobell a $30^{\circ} \mathrm{C}$ con agitación vigorosa por $16 \mathrm{~h}$. Posteriormente, las suspensiones bacterianas fueron diluidas en serie en agua marina artificial (Saulnier et al., 2000a). El número de unidades formadoras de colonias (ufc) de cada una de las suspensiones bacterianas $(100 \mu \mathrm{L})$ fue determinado por el método de extensión en superficie, siendo incubadas por 16 h a $27^{\circ} \mathrm{C}$ en placas con agar nutritivo Zobell para evaluar $a$ posteriori el número de bacterias usadas en el ensayo experimental. Todos los experimentos fueron conducidos en un área controlada debido a que $V$. penaeicida y $V$. nigripulchritudo son especies que no han sido reportadas en Tahiti. Los camarones ( $3.5 \mathrm{a} 5 \mathrm{~g}$ de peso) fueron infectados por inmersión de $2 \mathrm{~h}$ en $10 \mathrm{~L}$ de agua de mar filtrada y aireada conteniendo de 1 a $3.5 \times$ $10^{4} \mathrm{ufc} \mathrm{mL}^{-1}$ de una cepa bacteriana. Después del experimento se transfirireron lotes de 25 camarones a tanques cilindro cónicos de plástico con $100 \mathrm{~L}$ de agua de mar filtrada y aireada. Los camarones control fueron tratados de igual forma pero sin adicionar la cepa patógena. Por cada tratamiento se utilizaron dos tanques de cultivo como replica.

\section{Infección del SLC y de las FPs en camarón}

Se inyectaron camarones de 1.5 a $4.0 \mathrm{~g}$ de peso con $60 \mu \mathrm{L}$ de un SLC obtenido a 20 o $30^{\circ} \mathrm{C}$ de temperatura de incubación. Similarmente, algunos camarones fueron inyectados intramuscularmente con $20 \mu \mathrm{g}$ de proteína $\operatorname{org}^{-1}(20 \mu \mathrm{L})$ de las FPs40, FPs60 o FPs80 dializadas y obtenidas a partir de cada SLC o del control (BHI). Cada organismo fue inyectado intramuscularmente entre el tercer y cuarto segmento abdominal. Se usaron dos grupos de control (no inyectados e inyectados con $60 \mu \mathrm{L}$ de BHI). Cada tratamiento fue conducido por duplicado en tanques de plástico cilindro cónicos con $100 \mathrm{~L}$ de agua de mar filtrada con aireación, a una densidad de 20 a 25 camarones por tanque.

A fin de calcular una dosis letal media $\left(\mathrm{DL}_{50}\right)$ de las FPs40 de la cepa AM101, se inyectaron camarones (4 a 5 g de peso) a diferentes dosis $\left(1,5,10\right.$ y $20 \mu \mathrm{g}$ de proteína org $\left.^{-1}\right)$ usando el mismo protocolo descrito.

\section{Tratamiento térmico y químico de las FPs40}

Las FPs40 de las cepas AM101 y AM102 fueron sometidas a los siguientes tratamientos térmicos y químicos antes de ser inyectadas intra-muscularmente ( $20 \mu \mathrm{g}$ de proteína org $^{-1}$, cuantificados antes del tratamiento) como lo describen Montero y Austin (1999): (1) calentamiento a 60 y $100^{\circ} \mathrm{C}$ por $10 \mathrm{~min},(2)$ digestión con proteinasa $\mathrm{K}$ a una concentración final de $100 \mu \mathrm{g}$ $\mathrm{mL}^{-1}$, por $1 \mathrm{~h}$ a $37^{\circ} \mathrm{C}$, (3) exposición a inhibidor de tripsina de soya a una concentración final de $200 \mu \mathrm{g} \mathrm{mL} \mathrm{m}^{-1}$, o (4) exposición a EDTA a una concentración final de $100 \mu \mathrm{M}$. El grupo control de camarón fue inyectado con uno de los tres productos químicos a la misma concentración que la usada en el 
of $30 \%$ formaldehyde and $100 \mathrm{~mL}$ of distilled water; Harlow and Lane, 1988). A commercial molecular weight marker (BioRad, USA) was used in order to evaluate the size of the protein bands.

\section{Statistical analysis}

The mortality data were analyzed by Chi-square tests using the StatView software. Protein quantifications were compared by analysis of variance, multiple range test (Duncan) and correlation analysis using a Statistica software.

\section{Results}

\section{Pathogenicity of living Vibrio strains}

Significant differences in the strain pathogenicity were noticed when shrimp were infected by immersion with each of the three strains used at a similar infection dose (fig. 1). At day 4 post-infection, 60 and 54\% cumulative mortalities were observed for the AM101 and AM102 strains respectively, whereas the cumulative mortality for $\mathrm{KH}-1$ strain was only $12 \%\left(\chi^{2}=25\right.$ and 19.95 , respectively, $\left.P<0.0001\right)$. Shrimp survival in the KH-1-infected group was not significantly affected by the $V$. penaeicida infection compared to the control group $\left(\chi^{2}=2.17, P=0.13\right)$.

\section{Toxicity of CFS}

Even though Vibrio strains cultured at $30^{\circ} \mathrm{C}$ grew faster than those cultured at $20^{\circ} \mathrm{C}$, cultures incubated for 24 and $48 \mathrm{~h}$ showed similar turbidity and cell density at 490-nm

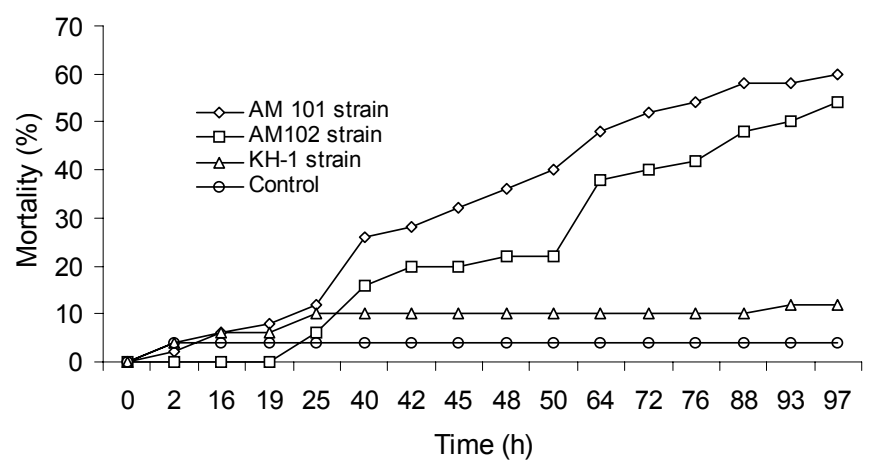

Figure 1. Mortality of $L$. stylirostris juveniles infected with living V. penaeicida strains $\mathrm{AM} 101$ and $\mathrm{KH}-1$, and $\mathrm{V}$. nigripulchritudo strain AM102, at $10^{4} \mathrm{cfu} \mathrm{mL}^{-1}$ after a 2-h bath challenge.

Figura 1. Mortalidad de juveniles de $L$. stylirostris infectados con las cepas vivas de V. penaeicida, AM101 y KH-1, y AM102 de V. nigripulchritudo, a $10^{4}$ ufc $\mathrm{mL}^{-1}$, después de $2 \mathrm{~h}$ del ensayo de inmersión. experimento. Los camarones inyectados fueron transferidos a tanques de plástico cilindro cónico con $100 \mathrm{~L}$ de agua de mar filtrada y aireada, a un densidad de 20 camarones por tanque.

Electroforesis de las FPs40 con geles de poliacrilamida (SDS-PAGE)

El perfil de las bandas proteicas de las FPs40 de las cepas AM101, KH-1 y AM102 fue obtenido por SDS-PAGE. Las FPs40 fueron desnaturalizadas en el buffer de la muestra por 10 min a $96^{\circ} \mathrm{C}$ (Laemmli, 1970) y corridas en un gel de SDSpoliacrilamida (Sambrook et al., 1989) a $110 \mathrm{~V}$ por $1.4 \mathrm{~h}$. Las bandas fueron teñidas con una solución de $0.2 \% \mathrm{AgNO}_{3}(200$ $\mu \mathrm{g}$ de $\mathrm{AgNO}_{3}, 75 \mathrm{~mL}$ de formaldehído al $30 \%$ y $100 \mathrm{~mL}$ de agua destilada) (Harlow y Lane 1988). Para evaluar el tamaño de las bandas proteicas se uso un marcador comercial de peso molecular (Bio-Rad, USA).

Análisis estadístico

Los datos de mortalidad fueron analizados con una prueba de Chi cuadrada usando el software StatView. La cuantificación de proteína fue comparada por medio de análisis de varianza, prueba de rango múltiple (Duncan) y correlación, usando para esto el software Statistica.

\section{Resultados}

Patogenicidad de las cepas vivas de Vibrio

Fue evidente una diferencia significativa en la patogenicidad de las cepas cuando los camarones fueron infectados por inmersión con cada una de las tres cepas usadas a una misma dosis de infección (fig. 1). A los 4 días después de la infeccción se observaron mortalidades acumuladas de 60 y $54 \%$ con las cepas AM101 y AM102, respectivamente, mientras que la mortalidad acumulada para los infectados con la cepa KH-1 fue de sólo $12 \%\left(\chi^{2}=25\right.$ y 19.95 respectivamente, $\left.P<0.0001\right)$. La sobreviviencia del grupo infectado con la cepa KH-1 no fue significativa con respecto al grupo control $\left(\chi^{2}=2.17\right.$, $P=0.13)$.

\section{Toxicidad del SLC}

Las cepas experimentales de Vibrio cultivadas a $30^{\circ} \mathrm{C}$ crecieron mas rápido que las cultivadas a $20^{\circ} \mathrm{C}$. Sin embargo, los cultivos obtenidos a las $24 \mathrm{~h}$ y $48 \mathrm{~h}$ de incubación mostraron turbidez y densidad celular similar a $490 \mathrm{~nm}$ de longitud de onda. Solo los SLC originados en los cultivos de las cepas AM101 y AM102 incubadas a $20^{\circ} \mathrm{C}$ inyectados a los camarones produjeron un porcentaje de mortalidad de 98 y $96 \%$, en lugar de 16 y $0 \%$ para los SLC provenientes de las mismas cepas cultivadas a $30^{\circ} \mathrm{C}$. Los controles (camarones no inyectados e inyectados con BHI) y los inyectados con el SLC de KH-1 presentaron una mortalidad del 2 al 5\% cuando los SLC fueron obtenidos a ambas temperaturas de cultivo. 
wavelength. The sterility of each CFS preparation was confirmed by the plate spreading method indicating that both bacterial centrifugation and filtration processes were successfully achieved. Only the CFS originating from AM101 and AM102 cultures incubated at $20^{\circ} \mathrm{C}$ exhibited 98 and $96 \%$ mortalities, compared to $16 \%$ and $0 \%$ of strains cultured at $30^{\circ} \mathrm{C}$. Control treatment (not injected and BHI-injected shrimp) and shrimp injected with $\mathrm{KH}-1 \mathrm{CFS}$ showed mortalities ranging from 2 to $5 \%$, at both culture temperatures.

\section{Toxicity of dialyzed PFs produced from CFS}

To study the in vivo toxicity of PFs for shrimp, protein concentrations of PFs40, PFs60, or PFs 80 obtained from each bacterial strain were first established. Protein fractions from strains AM101, KH-1 and AM102 revealed no significant differences $(P>0.05)$ for the same level of protein precipitation, whereas significant differences $(P<0.05)$ were observed between different fraction levels. The protein concentrations ranged from 0.5 to $0.6 \mathrm{mg} \mathrm{mL}^{-1}$ for PFs $40,0.7$ to $0.9 \mathrm{mg} \mathrm{mL}^{-1}$ for PFs60, and 1.1 to $1.2 \mathrm{mg} \mathrm{mL}^{-1}$ for PFs80. For each bacterial strain cultivated at $20^{\circ} \mathrm{C}$, a significant toxic activity was detected in PFs40 (fig. 2) compared to the toxicity obtained with either PFs60 or PFs80 $\left(\chi^{2}>6.4, P<0.013\right)$. When injected to shrimp, PFs40 from AM101 induced a higher mortality rate than PFs40 from KH-1 (90 and 60\%, respectively), $40 \mathrm{~h}$ after the injection. PFs 40 from AM102 showed the highest toxic effect since all the shrimp died after only 22
Toxicidad de las FPs dializado de del SLC

En el estudio de toxicidad de las FPs in vivo en camarón se estableció la concentración proteica de las FPs40, 60 y 80 de cada cepa bacteriana. Las FPs de las cepas AM101, KH-1 y AM102 no revelaron diferencias significativas $(P=0.05)$ para el mismo nivel de precipitación proteica, pero si se observó una diferencia significativa $(P<0.05)$ entre diferentes fracciones proteicas. El rango de proteína fue de 0.5 a $0.6 \mathrm{mg} \mathrm{mL}^{-1}$ para las FPs40, de 0.7 a $0.9 \mathrm{mg} \mathrm{mL}^{-1}$ para las FPs60 y de 1.1 a $1.2 \mathrm{mg} \mathrm{mL}^{-1}$ para las FPs80. Cuando cada cepa bacteriana fue cultivada a $20^{\circ} \mathrm{C}$ se detectó una toxicidad significativa en las FPs40 (fig. 2) comparada con la toxicidad obtenida con las FPs60 o FPs80 $\left(\chi^{2}>6.4, P<0.013\right)$. Cuando los camarones se inyectaron con FPs40 de AM101, el porcentaje de mortalidad fue mayor que en los tratados con FPs40 de KH-1 (90 y 60\%, respectivamente), a las $40 \mathrm{~h}$ de inyectados. La FPs40 de AM102 mostró el mayor efecto tóxico (100\% de mortalidad): todos los camarones murieron después de $22 \mathrm{~h}$ de ser inyectados. El porcentaje de mortalidad de los camarones de los otros grupos experimentales, incluyendo los grupos de las FPs60 y FPs 80 , fue del rango de 0 a $20 \%$ y no se presentó ninguna diferencia significativa al comparar con el grupo control que fue inyectado con BHI dializado $\left(\chi^{2}<2.06, P>0.15\right)$. $\mathrm{La} \mathrm{DL}_{50}$ aproximada de las FPs40 de AM101 fue estimada en alrededor de $5 \mu \mathrm{g}$ de proteína $\operatorname{org}^{-1} \mathrm{o} 1-1.25 \mu \mathrm{g}$ de proteína $\mathrm{g}^{-1}$ peso de los organismos, $59 \mathrm{~h}$ después de inyectados (fig. 3 ).
PFs40

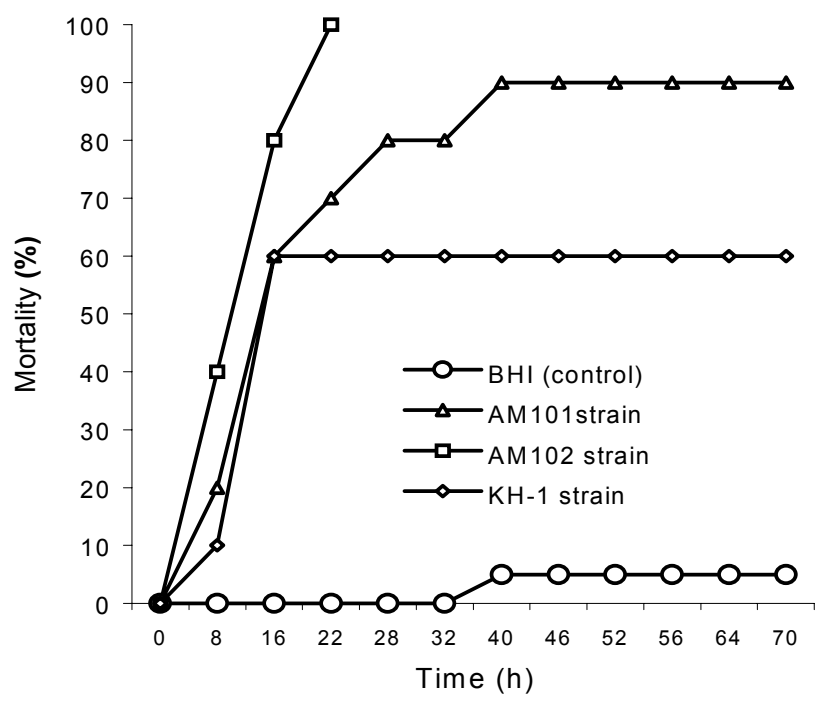

PFs60
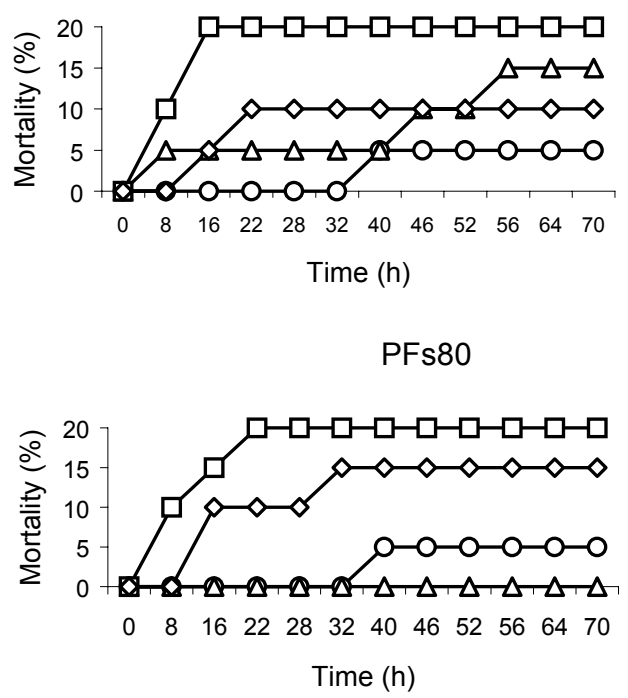

Figure 2. Mortality of $L$. stylirostris juvenile shrimp (2.5 to $4.0 \mathrm{~g}$ weight) intra-muscularly injected with $20 \mu \mathrm{ug}^{-1}$ of PFs40, PFs60 and PFs80 of $V$. penaeicida strains AM101 and $\mathrm{KH}-1$, and V. nigripulchritudo strain AM102.

Figure 2. Mortalidad de juveniles de camarón L. stylirostris (2.5 a $4.0 \mathrm{~g}$ de peso) inyectados intramuscularmente con $20 \mu \mathrm{gg}$ org ${ }^{-1}$ de FPs40, 60 y 80 de las cepas AM101 y KH-1 de V. penaeicida y AM102 de V. nigripulchritudo. 
hours post-injection. The mortality rates of shrimp in other experimental groups including PF60s and PF80s-treated groups ranged from 0 to $20 \%$ and were not significantly different from the one obtained in the control group injected with dialyzed BHI $\left(\chi^{2}<2.06, P>0.15\right)$. The approximate $\mathrm{LD}_{50}$ of PFs40 from AM101 was determined to be around $5 \mu \mathrm{g}$ protein org $^{-1}$ or $1-1.25 \mu \mathrm{g}$ protein $\mathrm{g}^{-1}$ body weight at $59 \mathrm{~h}$ post injection (fig. 3).

Effects of the thermal and chemical treatments on the toxicity of PFs40 from strains AM101 and AM102

Heat treatment for $10 \mathrm{~min}$ at $100^{\circ} \mathrm{C}$ completely inactivated the toxicity of PFs40 from strains AM102 and AM101 since any shrimp died during the survey period (data not shown) compared to the total mortality induced in the groups injected with non denatured raw PFs40 (fig. 4) . At moderate heating $\left(60^{\circ} \mathrm{C}\right.$ for $\left.10 \mathrm{~min}\right)$ the toxicity of PFs 40 from both strains was reduced, with 15 and $16 \%$ mortality rates, respectively, $40 \mathrm{~h}$ after injection. These extracts showed a delayed toxicity with 55 and $64 \%$ mortality rates, $70 \mathrm{~h}$ after their injection. The lethal toxicity of PFs40 from AM101 and AM102 was also affected by the proteinase $\mathrm{K}$ treatment showing mortality rates of 14 and $23 \%$, respectively, $32 \mathrm{~h}$ after the injection. Similarly to the heat treatment, a bimodal curve was observed after the proteinase $\mathrm{K}$ digestion of the extracts (fig. 4), with final mortality rates of 77 and $64 \%$, respectively, $70 \mathrm{~h}$ after injection. The EDTA and trypsin inhibitor treatments did not induce any effects on the in vivo toxicity of PFs40, showing mortality rates of $100 \%$ in both tests (data not shown).

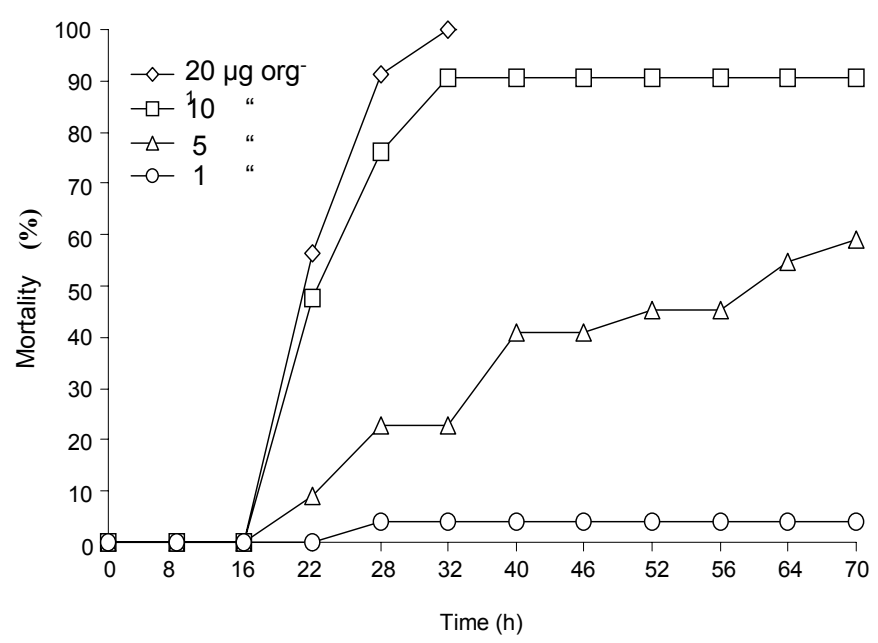

Figure 3. Mortality of $L$. stylirostris juvenile shrimp following intra-muscular injection with 20-, 10-, 5-, or 1- $\mu$ g protein org $^{-1}$ PFs40 of $V$. penaeicida strain AM101.

Figura 3. Mortalidad de juveniles de camarón $L$. stylirostris inyectados intra-muscularmente con 20, 10, 5, o $1 \mu \mathrm{g}$ proteína org $^{-1}$ de FPs40 de la cepa AM101 de V. penaeicida.
Efecto de los tratamientos térmicos y químicos sobre la toxicidad de las FPs40 de las cepas AM101 y AM102

El tratamiento de calor por 10 min a $100^{\circ} \mathrm{C}$ generó una completa inactivación de la toxicidad de las FPs40 de AM102 y AM101 ya que ningún camarón murió durante el periodo de prueba (datos no mostrados), en comparación con la mortalidad total inducida en el grupo inyectado con la FPs40 cruda (fig. 4). A una temperatura de $60^{\circ} \mathrm{C}$ por $10 \mathrm{~min}$, la toxicidad de las FPs40 de ambas cepas fue reducida, generando un porcentaje de mortalidad de 15 y $16 \%$, respectivamente, a las $40 \mathrm{~h}$ de ser inyectadas. Estos extractos mostraron una toxicidad diferida con un porcentaje de mortalidad de 55 y $64 \%, 70 \mathrm{~h}$ después de la inyección. La toxicidad de las FPs40 de AM101 y AM102 fue también afectada por el tratamiento con proteinasa $\mathrm{K}$ con un porcentaje de mortalidad del 14 y $23 \%$, respectivamente, a las $32 \mathrm{~h}$ de ser inyectadas. Al igual que con el tratamiento térmico, se observó una curva bimodal después de que los extractos fueron expuestos al tratamiento de digestión con proteinasa K (fig. 4), con un porcentaje de mortalidad final de 77 y $64 \%$, respectivamente, a las $70 \mathrm{~h}$ después de la inyección. Los otros tratamientos, con EDTA e inhibidor de tripsina de soya, mostraron no tener efecto en la toxicidad in vivo de las FPs40, con un porcentaje de mortalidad del $100 \%$ en ambas pruebas (datos no mostrados).

\section{SDS-PAGE de las FPs40}

Las FPs40 de las cepas AM102 de V. nigripulchritudo y AM101 y KH-1 de $V$. penaeicida fueron analizadas por

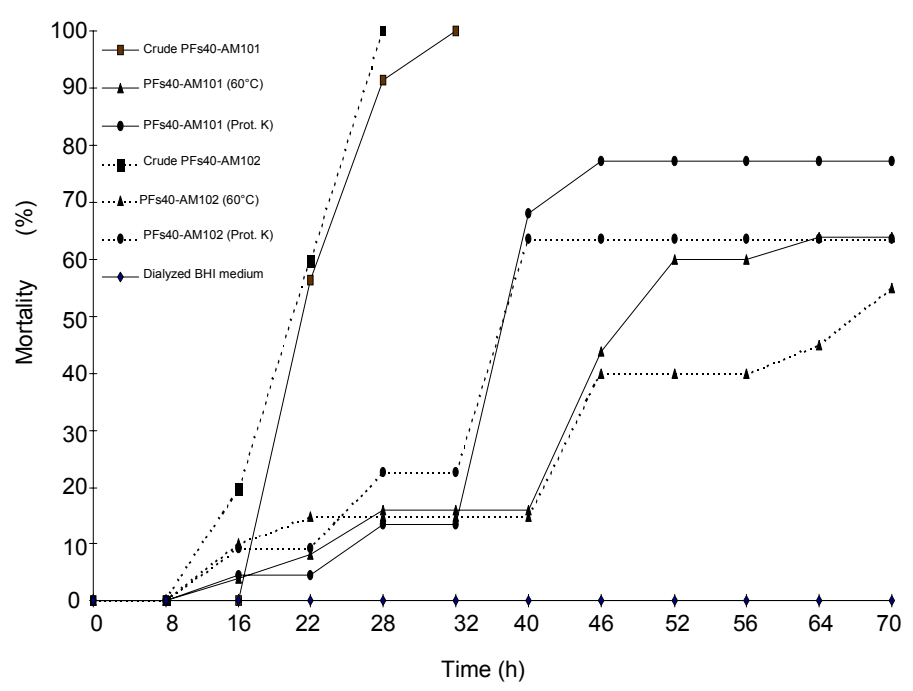

Figure 4. Mortality of $L$. stylirostris juvenile shrimp (4 to $5 \mathrm{~g}$ weight) injected intra-muscularly with $20-\mathrm{\mu g} \mathrm{org}^{-1} \mathrm{PFs} 40$ of $\mathrm{V}$. penaeicida strain AM101 and $V$. nigripulchritudo strain AM102, after proteinase $\mathrm{K}$ or heating treatment .

Figura 4. Mortalidad de juveniles de camarón $L$. stylirostris (4 a $5 \mathrm{~g}$ de peso) inyectados intra-muscularmente con $20 \mu \mathrm{g} \mathrm{org}^{-1}$ de FPs40 de las cepas de AM101 de V. penaeicida y AM102 de V. nigripulchritudo, después de su tratamiento con proteinasa $\mathrm{K}$ o calor 


\section{SDS-PAGE of PFs40}

Each PFs40 corresponding to $V$. nigripulchritudo strain AM102 and V. penaeicida strains AM101 and KH-1 were analyzed by SDS-PAGE (fig. 5). Unexpectedly, PFs40 obtained from these three strains displayed similar protein profiles, despite belonging to different Vibrio species or their distinct geographic origin (AM101 versus $\mathrm{KH}-1$ ). The PFs40 sample from BHI medium alone was also analyzed by SDS-PAGE as control, but no band was observed revealing the specificity of the detected protein bands (data not shown).

\section{Discussion}

Vibriosis is known to affect a wide range of fish and shellfish organisms (Lightner 1988; Brock and LeaMaster 1992). Vibrio penaeicida strains KH-1 and AM101 were involved in a major decline of the shrimp production in Japan (Takahashi et al., 1998) and New Caledonia (Costa et al., 1998), respectively. Our results showed that living strain KH-1 exhibited a very weak mortality rate (12\%) compared to strain AM101 (54\%) 4 days after infection, at a dose of $10^{4} \mathrm{cfu} \mathrm{mL}^{-1}$. Vibrio nigripulchritudo produced higher mortality $(60 \%)$ to shrimp. Saulnier et al. (2000a) reported similar results for strain AM101. Costa et al. (1998) showed a $\mathrm{LD}_{50}$ of $1.3 \times 10^{4} \mathrm{cfu}$ $\mathrm{mL}^{-1}$ for shrimp (L. stylirostris) by the bath challenge. De la Peña (1993) and Takahashi et al. (1998) reported that Vibrio sp PJ, later named $V$. penaeicida (Ishimaru et al., 1995), showed a $\mathrm{LD}_{50}$ of $10^{2}$ and $10^{3} \mathrm{cfu} \mathrm{org}^{-1}$ in juvenile $P$. japonicus when injected intramuscularly. Prayitno and Latchford (1995), Hameed (1995), Harris and Owens (1999), and Saulnier et al. (2000b) showed that the virulence of Vibrio species is related to the Vibrio strains, method of infection and host factors (species, age, physiological state).

This report shows the different pathogenicity effect and toxicity of the corresponding CFS and PFs40 of both reported $V$. penaeicida strains (KH-1 and AM101) for the same shrimp specie ( $L$. stylirostris) using the same infection doses and methods. This shows that both Vibrio strains may still have a specific difference which is demonstrated by the variation in their pathogenicity and toxicity (CFS and PFs40) effects on shrimp. Harris and Owens (1999) suggested the possible transmission of virulent factors to shrimp pathogen $V$. harveyi through the infection by a bacteriophage. Oakey and Owens (2000) reported isolating bacteriophages from a toxin-producing $V$. harveyi (strain 47666-1) in a moribund shrimp. Since bacteriophages are known to confer virulence to bacteria upon infection (Ruangpan et al., 1999), this may explain the common toxins found in this study. Complementary research needs to be carried out to explore the hypothesis of a toxin-producing bacteriophage. This may facilitate the understanding of their role in pathogenicity and mode of action.

The toxicity of CFS of pathogenic Vibrio strains on marine organism was demonstrated in vivo and in vitro, but the exact role of Vibrionaceae toxins in the pathogenesis of aquatic
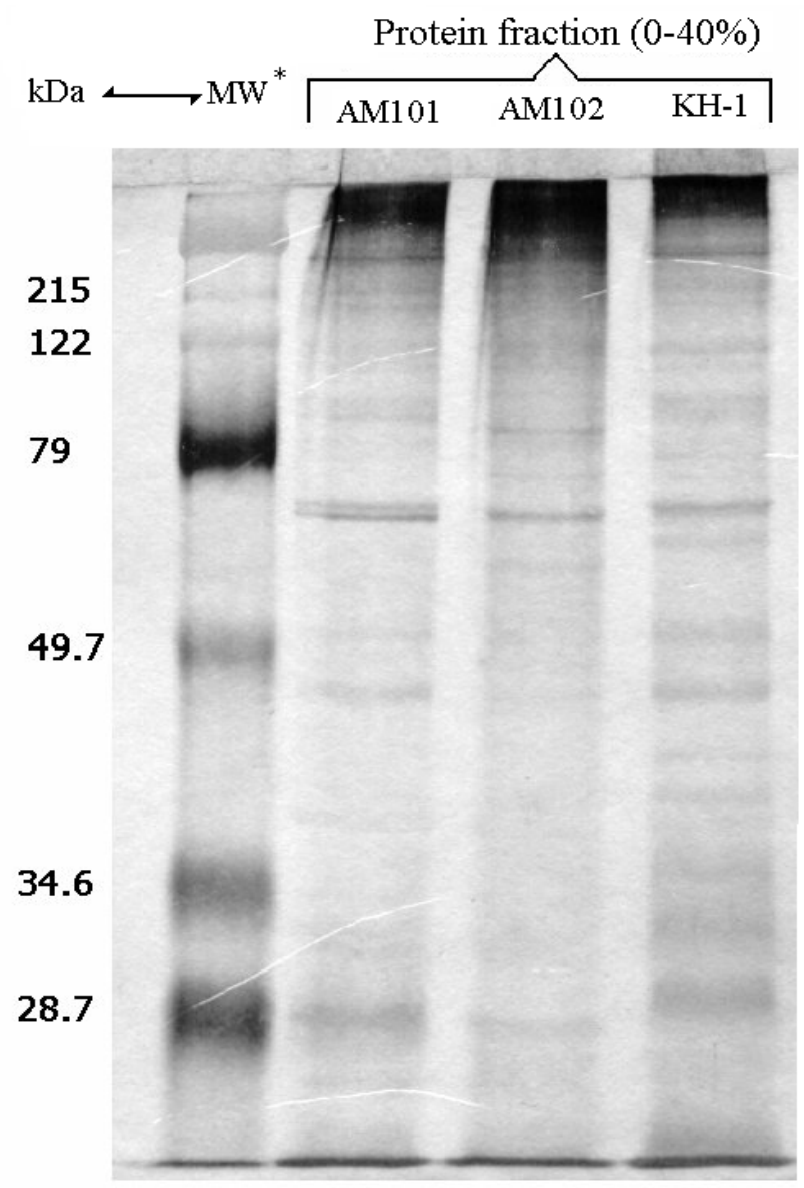

Figure 5. Electrophoretic profiles (SDS-PAGE 10\%) of PFs40 obtained from CFS of $V$. penaeicida strains $A M 101$ and $\mathrm{KH}-1$, and $V$. nigripulchritudo strain AM102, after silver nitrate staining.

Figura 5. Perfil electroforético (SDS-PAGE 10\%) de las FPs40 del SLC de las cepas AM101 y KH-1 de V. penaeicida y AM102 de V. nigripulchritudo, después de ser teñidas con nitrato de plata.

SDS-PAGE (fig. 5). Inesperadamente, las FPs40 obtenidas de las tres cepas mostraron un perfil electroforético similar, independientemente de la diferencia entre especies de Vibrio, o de su origen geográfico (AM101 versus $\mathrm{KH}-1$ ). La muestra de FPs40 del medio BHI fue analizada por SDS-PAGE como control, pero no se observaron bandas como las detectadas con las cepas (datos no mostrados).

\section{Discusión}

Se sabe que la vibriosis afecta a un amplio rango de peces y de organismos invertebrados (Lightner, 1988; Brock y LeaMaster, 1992). Las cepas KH-1 y AM101 de V. penaeicida estuvieron involucradas en el mayor declive de la producción de camarón en Japón (Takahashi et al., 1998) y en Nueva Caledonia (Costa et al., 1998), respectivamente. Los resultados de esta investigación demuestran que la cepa viva $\mathrm{KH}-1$ genera un bajo porcentaje de mortalidad (12\%) al compararse con la cepa AM101 (54\%), 4 días después de la infección a una dosis de $10^{4}$ ufc $\mathrm{mL}^{-1}$. La cepa de $V$. nigripulchritudo produjo la 
organisms is not well known yet (Liu et al., 1996; Lee et al., 1997; Sainz et al., 1998; Harris and Owens 1999; Montero and Austin 1999; Goarant et al., 2000). Vibrio exotoxin production is controlled by regulatory elements that are sensitive to environmental stress factors, such as high or low temperature (Pelczar et al., 1982). In this study, only the CFS produced at $20^{\circ} \mathrm{C}$ with $V$. penaeicida strain AM101 and $V$. nigripulchritudo strain AM102 showed high lethal effect on L. stylirostris shrimps, suggesting that CFS virulence is related to temperature-dependent conditions. Temperature-induced production of some virulence factors was suggested by Finlay and Falkow (1997). Our results confirm those obtained by Goarant et al. (2000) and also show that production of CFS toxicity is not cell density-dependent because, in both temperature treatments, Vibrio strains had similar cell densities.

To allow further characterization of the compounds involved in virulence, protein from each CFS were precipitated by adding increasing amounts of ammonium sulfate. Only the purified PFs 40 from cultures at $20^{\circ} \mathrm{C}$ showed a strong toxic effect on juvenile shrimp (compared to PFs60 and PFs80). Strains AM101 and AM102 PFs40 were lethal to shrimp (> 90\% mortality) and KH-1 PFs40 showed a toxic activity (at the same $20-\mu \mathrm{g} \mathrm{org}^{-1}$ dose) causing $60 \%$ mortality. Strain KH-1 may produce a low quantity of the exotoxic factor, however, the purification method used in this study resulted in concentrated protein fractions. This was probably the main cause of the mortality exhibited by KH-1, which showed higher pathogenicity in juvenile shrimp $L$. vannamei $(2.5$ to $3.5 \mathrm{~g}$ weight) (Aguirre et al., data not published).

Interestingly, heat and proteinase $\mathrm{K}$ treatments on PFs 40 of strains AM101 and AM102 produced a similar toxicity inhibition. The loss of toxicity after proteinase $\mathrm{K}$ digestion and the fact that CFS could be precipitated by ammonium sulfate strongly suggest a proteinaceous nature of the putative virulence factor. The evidence of residual toxic activity could correspond to insufficient time for the proteinase $\mathrm{K}$ digestion or to the presence of other non-proteinaceous exotoxins like lipopolysaccharides in CFS (Montero and Austin 1999). The results of the heat treatment point to the relative thermolability of this exotoxin factor. Other treatments at PFs40, such as EDTA and trypsin inhibitor, had no effects on the in vivo toxicity, suggesting that metalloprotease or trypsine-like protease are not the toxic factors involved in the virulence of these strains.

The in vivo toxicity for the PFs 40 of AM101 was estimated at $5 \mu \mathrm{g}$ protein $\operatorname{org}^{-1}$ or $1-1.25 \mu \mathrm{g}$ protein $\mathrm{g}^{-1}$ body weight. These values can be compared to the $\mathrm{LD}_{50}$ reported in studies about CFS prepared from $V$. parahaemolyticus and $V$. harveyi: 8 and $4.4 \mu \mathrm{g}$ protein org $^{-1}$ (Sudheesh and $\mathrm{Xu}, 2001$; Montero and Austin, 1999), $1.2-1.5$ and 1.8-2.2 $\mu \mathrm{g}$ protein $\mathrm{g}^{-1}$ body weight (Liu et al., 1996; Harris and Owens, 1999). All this $\mathrm{LD}_{50}$ were obtained by intra-muscular injection of CFS in juvenile P. monodon and L. vannamei. This is the first report of the toxicity of a proteinaceous exocellular toxin-like factor on two different $V$. penaeicida strains and a $V$. nigripulchritudo mayor mortalidad (60\%) de camarón. Saulnier et al. (2000a) reportaron resultados similares para la cepa AM101. Costa et al. (1998) mostraron una $\mathrm{DL}_{50}$ de $1.3 \times 104 \mathrm{ufc} \mathrm{mL}^{-1}$ para camarón (L. stylirostris) en un ensayo por inmersión. De la Peña (1993) y Takahashi et al. (1998) reportaron que Vibrio sp $\mathrm{PJ}$, posteriormente llamado $V$. penaeicida (Ishimaru et al., 1995), mostró una $\mathrm{DL}_{50}$ de $10^{2}$ y $10^{3} \mathrm{ufc} \mathrm{org}^{-1}$ en juveniles de $P$. japonicus, cuando éstos fueron inyectados intramuscularmente. Prayitno y Latchford (1995), Hameed (1995), Harris y Owens (1999) y Saulnier et al. (2000b) demostraron que la virulencia de las especies de Vibrio está relacionada con la cepa de Vibrio, el método de infección y las características del huésped (especie, edad, estado fisiológico).

En este reporte se evidencia el diferente efecto patogénico y tóxico de los SLC y las FPs40 de las dos cepas (KH-1 y AM101) de $V$. penaeicida sobre una misma especie de camarón (L. stylirostris) y usando igual dosis y método de infección. Esto demuestra que tales cepas de Vibrio poseen alguna diferencia específica, lo cual es demostrado por la variación en sus efectos de patogenicidad y toxicidad (SLC y FPs40) sobre camarón. Harris y Owens (1999) sugieren la posible transmisión de factores virulentos hacia el patógeno del camarón $V$. harveyi, a través de la infección de un bacteriófago. Oakey y Owens (2000) reportan haber aislado un bacteriófago de una cepa de $V$. harveyi productora de toxinas (47666-1) proveniente de camarones moribundos. Se sabe que los bacteriofagos pueden conferir virulencia a las bacterias (Ruangpan et al., 1999), lo que podría explicar la toxicidad en común encontrada en las cepas de estudio. Son necesarias investigaciones complementarias a fin de explorar la hipótesis de la producción de toxinas provenientes de bacteriófagos ya que éstas facilitarían la comprensión de su papel en la patogenicidad y la manera cómo actuan.

La toxicidad del SLC de cepas patogénicas de Vibrio en organismos marinos ha sido demostrada in vivo e in vitro pero el papel exacto de las toxinas Vibrionaceas en la patogenicidad sobre organismos acuáticos todavía no es bien conocido (Liu et al., 1996; Lee et al., 1997; Sainz et al., 1998; Harris y Owens, 1999; Montero y Austin 1999; Goarant et al., 2000). La producción de exotoxinas de Vibrio es controlada por elementos regulatorios que son sensibles a los factores estresantes ambientales tales como alta y baja temperatura (Pelczar et al., 1982). En este estudio, solo el SLC producido por las cepas AM101 de V. penaeicida y AM102 de V. nigripulchritudo, cultivadas a $20^{\circ} \mathrm{C}$, mostraron tener un mayor efecto letal sobre el camarón L. stylirostris, sugiriendo que la virulencia del SLC está relacionada con una condición dependiente de la temperatura. La temperatura induce la producción de algunos factores virulentos, lo cual fue sugerido por Finlay y Falkow (1997). Nuestros resultados confirman lo obtenido por Goarant et al. (2000), y también muestran que la toxicidad del SLC no depende de la densidad celular porque a ambas temperaturas de cultivo las cepas de Vibrio tenían una densidad celular similar.

A fin de caracterizar los componentes involucrados en la virulencia, las proteínas de cada SLC fueron precipitadas por 
strain with similar protein profiles in their corresponding PFs40, as revealed by the SDS-PAGE and silver staining methods. This observation and the fact that CFS of $V$. penaeicida strain AM101 and $V$. nigripulchritudo strain AM102 show the same susceptibility level to proteinase $\mathrm{K}$, heat and inhibitor treatments suggest a common putative exotoxinic component.

\section{Acknowledgments}

Thanks for the funding from the Mexican Council of Science and Technology (CONACyT) project 132908, the Cortez Sea Research System (SIMAC) project 980106033, the Northwest Center for Biological Research (CIBNOR) project ABM-11. F.A. holds a graduate scholarship from CONACyT. This study was facilitated by an academic exchange program CIBNOR-Centre Océanologique du Pacifique (COP). Vibrio penaeicida $\mathrm{KH}-1 \mathrm{~T}$ was donated by Leonardo Lizarraga (Centro de Investigación Científica y de Educación Superior de Ensenada), $V$. penaeicida AM101 and $V$. nigripulchritudo AM102 were provided by D. Saulnier (COP-IFREMER, Tahiti, French Polynesia). Thanks to Aquapac, Co. in Tahiti for supplying shrimp and to Ira Fogel at CIBNOR for the editorial advice.

\section{References}

Alapide-Tendencia, E.V. and Dureza, L.A. (1997). Isolation of Vibrio spp. from Penaeus monodon (Fabricius) with red disease syndrome. Aquaculture, 154: 107-114.

Brock, J.A. and LeaMaster, B. (1992). A look at the principal bacterial, fungal and parasitic diseases of farmed shrimp. In: J. Wyban (ed.), Proceedings of the special session on shrimp farming. World Aquaculture Society, Baton Rouge, LA. pp. 212226.

Costa, R., Mermoud, I., Koblavi, S., Morlet, B., Haffner, P., Berthe, F., Legroumellec, M., and Grimont, P. (1998). Isolation and characterization of bacteria associated with a Penaeus stylirostris disease (Syndrome 93) in New Caledonia. Aquaculture, 164: 297309.

de la Peña, L.D., Tamaki, K.T., Momoyama, T.N. and Muroga, K. (1993). Characteristics of causative bacterium of vibriosis in kuruma prawn, Penaeus japonicus. Aquaculture, 115:1-12.

de la Peña, L.D., Nakai, T. and Muroga, K. (1995). Dynamics of Vibrio sp. PJ in organs of orally infected kuruma prawn, Penaeus japonicus. Fish Pathol., 30: 39-45.

Finlay, B.B. and Falkow, S. (1997). Common terms in microbial pathogenicity revised. Microbiol. Mol. Biol. Rev., 61:136-169.

Fukasawa, S., Nakamura, K., Miyahira, M. and Kurata, M. (1988). Some properties of two proteinases from a luminous bacterium, Vibrio harveyi strain FLN-108. Agric. Biol. Chem., 52: 30093014.

Goarant, C., Régnier, F., Brizard, R. and Marteau, A.L. (1998). Acquisition of susceptibility to Vibrio penaeicida in Penaeus stylirostris postlarvae and juveniles. Aquaculture, 169: 291-296.

Goarant, C., Merien, F., Berthe, F., Mermoud, I. and Perolat, P. (1999). Arbitrarily Primed PCR To Type Vibrio spp. Pathogenic for Shrimp. Appl. Environ. Microbiol., 65: 1145-1151. adición creciente de sulfato de amonio. Sólo las FPs40 purificadas de los cultivos a $20^{\circ} \mathrm{C}$ desarrollaron un potente efecto tóxico sobre los juveniles de camarón (en comparación con las FPs60 y FPs80). Las FPs40 de AM101 y AM102 fueron letales para el camarón ( $>90 \%$ de mortalidad) y las FPs40 de KH-1 desarrollaron una actividad tóxica (a la misma dosis de $20 \mu \mathrm{g} \mathrm{org}^{-1}$ ) con $60 \%$ de mortalidad. La cepa KH-1 puede estar produciendo una menor cantidad del factor exotóxico, sin embargo, el método de purificación empleado en este estudio resultó útil para obtener la fracción proteica concentrada. Ésta fue, probablemente, la principal razón por la que se observó mortalidad en KH-1, la cual mostró tener un mayor efecto patogénico en juveniles de camarón L. vannamei $(2.5$ a $3.5 \mathrm{~g}$ de peso) (Aguirre et al., datos no publicados).

De manera interesante, los tratamientos con calor y proteinasa K de las FPs40 de las cepas AM101 y AM102 produjeron una inhibición similar de la toxicidad. La perdida de toxicidad después de la digestión con proteinasa $\mathrm{K}$, y el hecho de que el SLC pudo ser precipitado con sulfato de amonio, sugieren fuertemente una naturaleza proteica del factor virulento. La evidencia de una actividad tóxica residual puede corresponder a un tiempo insuficiente en la digestión con la proteinasa $\mathrm{K}$, o a la presencia de otra exotoxina no proteica, como los lipopolisacaridos, en el SLC (Montero y Austin 1999). El resultado del tratamiento con calor indica una relativa termolabilidad de este factor exotóxico. Los otros tratamientos aplicados a las FPs40, como la aplicación de EDTA o el inhibidor de tripsina, no tuvieron efecto en la toxicidad in vivo, sugiriendo que las metaloproteasas o proteasas de tipo tripsina no participan en la virulencia del factor tóxico de estas cepas.

La toxicidad in vivo para las FPs40 de AM101 fue estimada en $5 \mu \mathrm{g}$ de proteína org $^{-1}$ o $1-1.25 \mu \mathrm{g}$ de proteína $\mathrm{g}^{-1}$ de peso corporal. Estos valores pueden ser comparados con la $\mathrm{DL}_{50}$ reportada en los estudios del SLC preparado a partir de $V$. parahaemolyticus y $V$. harveyi: 8 y $4.4 \mu \mathrm{g}$ de proteína org $^{-1}$ (Sudheesh y Xu 2001; Montero y Austin 1999), y 1.2-1.5 y 1.8-2.2 $\mu \mathrm{g}$ de proteína $\mathrm{g}^{-1}$ peso corporal (Liu et al., 1996; Harris y Owens 1999). Todas las $\mathrm{DL}_{50}$ fueron obtenidas por inyecciones intra-musculares del SLC en juveniles de P. monodon y L. vannamei. Éste es el primer reporte de un factor tóxico extracelular y con un perfil electroforético similar en las FPs40 de las dos diferentes cepas de $V$. penaeicida y de la cepa de $V$. nigripulchritudo, como fue observado por el método de SDS-PAGE y la tinción con plata. Esta observación $\mathrm{y}$ el hecho de que los SLC de las cepas AM101 de $V$. penaeicida y AM102 de $V$. nigripulchritudo muestran un mismo nivel de susceptibilidad a la proteinasa $\mathrm{K}$, al calor y a otros tratamientos de inhibición, sugieren la presencia de un componente tóxico en común.

\section{Agradecimientos}

Se agradece el apoyo del Consejo Nacional de Ciencia y Tecnología (CONACyT) proyecto 132908, el Sistema de Investigación del Mar de Cortez (SIMAC) proyecto 
Goarant, C., Herlin, J., Brizard, R., Marteau, A.L., Martin, C. and Martin, B. (2000). Toxic factors of Vibrio stains pathogenic to shrimp. Dis. Aquat. Org., 40: 101-107.

Hameed, A.S.S. (1995). Susceptibility of three Penaeus species to a Vibrio campbellii-like Bacterium. J. World Aquaculture Soc., 26: 315-318.

Harlow, E. and Lane, D. (1988). Antibodies, A laboratory manual. Ed. Cold Spring Harbor Laboratory. Second edition. New York. pp. 156.

Harris, L.J. and Owens, L. (1999). Production of exotoxins by two luminous Vibrio harveyi strains known to be primary pathogens of Penaeus monodon larvae. Dis. Aquat. Org., 38: 11-22.

Hernández-Sontoyo, A., Hernández-Arana, A., Arreguín-Espinosa, R. and Rodríguez-Romero, A. (1998). Purification and characterization of several digestive proteases from the blue abalone Haliotis fulgens. Aquaculture, 159: 203-216.

Hörmansdorfer, S., Wentges, H., Neugebaur-Büchler, K. and Bauer, J. (2000). Isolation of Vibrio alginolyticus from seawater aquaria. Int. J. Hyg. Environ. Health, 203: 169-175.

Ishimaru, K.M., Akagawa, M. and Muroga, K. (1995). Vibrio penaeicida sp nov. A pathogen of kuruma shrimp (Penaeus japonicus). Int. J. Syst. Bacteriol., 1: 134-138.

Jiravanichpaisal, P., Miyazaki, T. and Limsuwan, C. (1994). Histopathology, biochemistry, and pathogenicity of Vibrio harveyi infecting black tiger prawn Penaeus monodon. J. Aquat. Anim. Health, 61: 27-35.

Karunasagar, I., Pai, R., Malathi, G.R. and Karunasagar, I. (1994). Mass mortality of Penaeus monodon larvae due to antibioticresistant Vibrio harveyi infection. Aquaculture, 128: 203-209.

Laemmli, U.K. (1970) Cleavage of structural proteins during the assembly of the head of bacteriophage T4. Nature 227: 680-685.

Le Groumellec, M., Goarant, C., Haffner, P., Mermoud, I., and Costa, R. (1996). Study of episodes of mortality observed in reared Penaeus stylirostris since 1993 in New Caledonia: IV Investigation of the bacterial hypothesis by experimental infections, with reference to stress-induced mortality. Annual Meeting of the World Aquaculture Society. January 29-February 2, 1996. Bangkok, Thailand, pp. 144.

Lee, K.K., Yu S.R. and Liu, P.C. (1997). Alkaline serine protease is an exotoxin of Vibrio alginolyticus in kuruma prawn, Penaeus japonicus. Curr. Microbiol., 34: 110-117.

Lee, K.K., Chen, Y.L. and Liu, P.C. (1999). Hemostasis of tiger prawn Penaeus monodon affected by Vibrio harveyi, extracellular products and a toxic cysteine protease. Blood Cell. Mol. Dis., 25: 180-192.

Lightner, D.V. (1988). Vibrio disease of Penaeid shrimp. Disease Diagnosis and control in North American marine aquaculture. In: C.J. Sindermann and D. Lightner (eds.), Devlopments in aquaculture and fisheries science. Elsevier, Amsterdam. pp. 4247.

Lightner, D.V. (1996). Disease of culture penaeid shrimp. In: J. P. McVey (ed.), Handbook of Mariculture. Crustacean Aquaculture. 2nd Ed. CRC Press. Boca Raton, FL.

Liu, P.C., Lee, K.K. and Chen, S.N. (1996). Pathogenicity of different isolates of Vibrio harveyi in tiger prawn, Penaeus monodon. Let. Appl. Microbiol., 22: 413-416.

Montero, A.B. and Austin, B. (1999). Characterization of extracellular products from an isolate of Vibrio harveyi recovered from diseased post-larval Penaeus vannamei (Bonne). J. Fish Dis., 22: $377-386$.
980106033, el Centro de Investigaciones Biológicas del Noroeste (CIBNOR) proyecto ABM-11 de F.A. y una beca mixta del CONACyT; las facilidades de un programa de intercambio académico entre CIBNOR y el Centre Océanologique du Pacifique (COP), de IFREMER. La cepa de $V$. penaeicida KH-1 fue donada por Leonardo Lizarraga (Centro de Investigación Científica y de Educación Superior de Ensenada), y las cepas $V$. penaeicida AM101 y V. nigripulchritudo AM102 fueron suministradas por D. Saulnier (COP; Tahití, Polinesia Francesa). Se agradece a la granja Aquapac, Co. de Tahití por el suministro del camarón y a Ira Fogel (CIBNOR) por su trabajo en la edición de la versión en inglés de este trabajo.

Traducción al español por los autores.

Oakey, H.J. and Owens, L. (2000). A new bacteriophage, VHML, isolated from a toxin-producing strain Vibrio harveyi in tropical Australia. J. Appl. Micriobiol., 89: 702-709.

Ohnishi, S.T. and Barr, J.K. (1978). A simplified method of quantitating proteins using the biuret and phenol reagents. Anal. Biochem., 86: 193.

Pelczar, M.J., Reid, R.D. and Chan, E.C.S. (1982). Microbiología. McGraw-Hill., México. pp. 1-120.

Prayitno, S.B. and Latchford, J.W. (1995). Experimental infections of crustaceans with luminous bacteria related to Photobacterium and Vibrio. Effect of salinity and $\mathrm{pH}$ on infectiosity. Aquaculture, 132: 105-112.

Robertson, P.A.W., Calderon, J., Carrera, L., Stark, J.R., Zherdmant, M. and Austin, B. (1998). Experimental Vibrio harveyi infections in Penaeus vannamei larvae. Dis. Aquat. Org., 32: 151-155.

Ruangpan, L., Danayadol, Y., Direkbusarakom, S., Siurairatana, S. and Flegel, T.W. (1999). Lethal toxicity of Vibrio harveyi to cultivated Penaeus monodon induced by a bacteriophage. Dis. Aquat. Org., 35: 195-201.

Sainz, J.C., Maeda-Martínez, A.N. and Ascencio, F. (1998). Experimental vibriosis induction with Vibrio alginolyticus of larvae of the catarina scallop (Argopecten ventricosus = circularis)(Sowerby II, 1842). Microb. Ecol., 35: 188-192.

Sambrook, J., Fritsch, E.F. and Maniatis, T. (1989). Molecular cloning, A laboratory manual. Ed. Cold Spring Harbor Laboratory. Second edition. New York, pp. 1-18.

Saulnier, D., Haffner, P., Goarant, C., Levy, P. and Ansquer, D. (2000a). Experimental infection models for shrimp vibriosis studies: a review. Aquaculture, 191: 133-144.

Saulnier, D., Avarre, J.C., Le Moullac, G., Ansquer, D., Levy, P. and Vonau, V. (2000b). Rapid and sensitive PCR detection of Vibrio penaeicida, the putative etiological agent of Syndrome 93 in New Caledonia. Dis. Aquat. Org., 40: 109-115.

Scopes, R. (1998). Protein purification, principles and practice. Springer-Verlag. Second Edition. New York, pp. 301-310.

Sudheesh, P.S. and $\mathrm{Xu}$, H.S. (2001). Pathogenicity of Vibrio parahaemolyticus in tiger prawn Penaeus monodon Fabricius: possible role of extracellular proteases. Aquaculture, 196: 37-46.

Takahashi, Y., Itami, T., Maeda, M. and Kondo, M. (1998). Bacterial and viral diseases of kuruma shrimp (Penaeus japonicus) in Japan. Fish Pathol., 33: 357-364. 